\title{
APRENDIZAGEM EM COMUNIDADES DE PRÁTICA: ESTUDO EM UM GRUPO DE PESQUISA
}

\author{
COMMUNITIES OF PRACTICE: A STUDY IN A RESEARCH \\ GROUP
}

\section{EL APRENDIZAJE EN COMUNIDADES DE PRÁCTICA: ESTUDIO EN UN GRUPO DE INVESTIGACIÓN}

\section{Raquel Engelman}

Professora pesquisadora da Universidade Feevale, Brasil / Doutora em administração pela Universidade Federal do Rio Grande do Sul (UFRGS), Brasil raqueleng@feevale.br

\author{
Dusan Schreiber \\ Professor adjunto e pesquisador da Universidade \\ Feevale, Brasil / Doutor em administração pela \\ Universidade Federal do Rio Grande do Sul (UFRGS), \\ Brasil \\ dusan@feevale.br
}

\section{Maria Cristina Bohnenberger}

Professora e pesquisadora da Universidade Feevale, Brasil / Doutora em administração pela Universidade das Ilhas Baleares, Espanha

cristin@feevale.br

\section{Vânia Gisele Bessi}

Professora da Universidade Feevale, Brasil / Doutora em administração pela Universidade Federal do Rio Grande do Sul (UFRGS), Brasil

vania@feevale.br

\author{
Contextus \\ ISSNe 2178-9258 \\ Organização: Comitê Científico Interinstitucional \\ Editor Científico: Carlos Adriano Santos Gomes \\ Avaliação: double blind review pelo SEER/OJS \\ Edição de texto e de layout: Carlos Daniel Andrade \\ Recebido em 11/05/2017 \\ Aceito em 23/10/2017 \\ $2^{a}$ versão aceita em $07 / 11 / 2017$
}

\begin{abstract}
RESUMO
A Teoria da Aprendizagem Situada considera a aprendizagem como socialmente construída e fundamentada em situações concretas e o conhecimento não como primariamente abstrato e simbólico, mas como provisório, mediado e socialmente construído, com significados intersubjetivos atribuídos às práticas compartilhadas na organização. A presente pesquisa teve como objetivo compreender, à luz da abordagem de Aprendizagem Situada, o processo de aprendizagem em um grupo de pesquisa concebido como comunidade de prática, de uma universidade pública, do sul do país. Os dados foram coletados a partir de observação não participante, pelo período de três meses, no laboratório onde o grupo trabalha, além de 12 entrevistas semiestruturadas. Com base nos dados coletados, foi possível identificar, em diferentes graus, diversos elementos de comunidades de prática apresentados pela teoria selecionada, tais como o ambiente/contexto, a liderança, a conectividade, a aprendizagem formal/informal e artefatos não humanos.
\end{abstract}

Palavras-chave: Aprendizagem. Teoria da Aprendizagem Situada. Comunidades de prática. Conhecimento. Grupos de pesquisa.

\section{ABSTRACT}

Situated Learning Theory considers that learning is socially constructed and based on concrete situations and that knowledge is primarily not abstract and symbolic but rather provisional, mediated and socially constructed, having intersubjective meanings ascribed to practices shared at the organization. The aim of this research was to understand in the light of the situated learning approach the learning process of a research group conceived of as 
a community of practice at a public university in Brazil's south. Data were collected both from a three-month period non-participant observation in the laboratory where the group works and from 12 semi-structured interviews. Based on the results, it was possible to identify to different extents communities of practice elements presented by the theory in question such as environment/context, leadership, connectivity, formal/informal learning and non-human artifacts.

Keywords: Learning. Situated Learning Theory. Communities of Practice. Knowledge. Research Groups.

\section{RESUMEN}

La teoría de aprendizaje situado considera que el aprendizaje es una construcción social basada en situaciones concretas y el conocimiento no es fundamentalmente abstracto y simbólico sino provisional, mediado y socialmente construido, con significados intersubjetivos atribuidos a las prácticas comunes en la organización. La presente investigación tuvo como objetivo comprender, a la luz del enfoque de aprendizaje situado, el proceso de aprendizaje en un grupo de investigación concebido como comunidad de práctica, en una universidad pública, en el sur de Brasil. Los datos fueron recolectados desde la observación no participante por un período de tres meses en el laboratorio donde trabaja el grupo y desde 12 entrevistas semiestructuradas. Con base en los resultados, se identificaron pruebas presentadas por la teoría seleccionada en diferentes grados, tales como el ambiente / contexto, el liderazgo, la conectividad, el aprendizaje formal / informal y los artefactos no humanos.

Palabras-clave: El aprendizaje. Situado en la teoría del aprendizaje. Comunidades de práctica. Conocimiento. Grupos de investigación.

\section{INTRODUÇÃO}

As práticas e teorias organizacionais sobre aprendizagem se difundiram sobremaneira tanto nas pesquisas em administração, quanto nas organizações, o que pode ser observado pelo número de publicações, eventos e referências ao tema em diferentes contextos (BASTOS; GONDIM; LOIOLA, 2004; EASTERBY-SMITH; SNELL; GHERARDI, 1998; ELKJAER， 2001). Segundo Antonello e Godoy (2011), o tema se popularizou e serve como "guardachuva" para diversos conceitos relacionados, com ramificações na educação, psicologia, sociologia, ciência da computação e economia. Com mais de 30 anos de legado, diversas revisões de literatura e uma diversidade de perspectivas, algumas abordagens buscam distanciar-se da tradicional
(ANTONELLO; GODOY, 2011), ao conceber a aprendizagem em geral como socialmente construída e fundamentada em situações concretas, nas quais as pessoas participam e interagem umas com as outras.

Nessa perspectiva, a Teoria da Aprendizagem Situada de Lave e Wenger (1991) oferece uma crítica às teorias cognitivistas de aprendizagem organizacional, questionando principalmente o pressuposto pedagógico de aprendizagem como atividade descontextualizada. Para Handley et al. (2006), a idealização cognitivista baseia-se em uma avaliação positivista do conhecimento abstrato, segundo a qual este deve ser privilegiado por supostamente refletir uma realidade objetiva e poder ser plenamente manipulado usando a lógica racionalista e simbólica. 
A Teoria da Aprendizagem Situada, em contrapartida, argumenta que o foco cognitivista no conhecimento abstrato é enganoso, porque ignora, por exemplo, a dimensão em grande parte tácita das práticas de trabalho. Conforme sugere a nova abordagem, o aprendizado individual deve ser pensado como emergente, envolvendo oportunidades de participação nas práticas da comunidade, bem como o desenvolvimento de uma identidade que proporciona sensação de pertencimento e compromisso. Assim, o conhecimento não é mais visto como primariamente abstrato e simbólico, mas como provisório, mediado e socialmente construído (HANDLEY et al., 2006), com significados intersubjetivos atribuídos a práticas compartilhadas (WENGER, 1998; YANOW, 2000).

A aprendizagem, por esse ângulo, é entendida como aspecto integrante e inseparável da prática social que envolve a construção de identidade através de novas formas de participação nas chamadas comunidades de prática (HANDLEY et al., 2006). O conceito de comunidades de prática, que embasa este trabalho, foi proposto pelas obras seminais de Lave e Wenger (1991) e de Brown e Duguid (1991) e tornou-se popular em vários campos acadêmicos, incluindo estudos organizacionais.
Considerando as mudanças da academia no Brasil voltadas à excelência, inclusive na formação de pesquisadores, no aumento da produtividade científica nos programas de pós-graduação e em uma maior inserção internacional, compreender como ocorre a aprendizagem em grupos de pesquisa torna-se um tema de relevância. Além disso, em um programa de pósgraduação, adquirir, compartilhar e criar conhecimento são o foco principal.

Nesse sentido, esta pesquisa teve como objetivo compreender o processo de aprendizagem em comunidades de prática, em um grupo de pesquisa, à luz da abordagem de Lave e Wenger (1991) e Wenger (1998), usando o modelo de análise desenvolvido em Wenger (2003; 2013). Também, com o intuito de proporcionar um maior conhecimento sobre o tema, procurou-se identificar possíveis categorias de análise para futuras comparações com outros grupos de pesquisa. Salienta-se, de antemão, que este trabalho não pretende discutir o mérito das referidas exigências impostas aos grupos de pesquisa, tampouco discutir as implicações éticas no âmbito da educação nas instituições de ensino superior.

Para a realização da pesquisa, foi escolhido o grupo de pesquisa Ecologia Quantitativa do Programa de PósGraduação em Ecologia da UFRGS, pois 
ele, além de poder ser considerado uma comunidade de prática, é referência em sua área de conhecimento devido à qualidade das pesquisas e ao volume de produção científica. Este trabalho se inicia com dois capítulos teóricos sobre a Teoria da Aprendizagem Situada e comunidades de prática. Em seguida, apresenta o método do estudo, o grupo de pesquisa objeto da análise e a discussão dos resultados.

\section{TEORIA DA APRENDIZAGEM SITUADA}

A teoria da ação situada contrapõese à descontextualização como pretensa condição de objetividade. Faz assim uma crítica a modelos racionalistas em favor da interpretação contextualizada da ação social, visando substituir a dita racionalidade objetiva, representada na forma de um conjunto de tarefas a serem realizadas no âmbito da lógica do “otimizar", pela "racionalidade contextual", voltada à lógica da situação. O contexto em que se realiza o trabalho não é dado, mas ativamente "construído" em vários "quadros situacionais" que interpretam as situações de corte do ambiente (ANTONELLO; AZEVEDO, 2011; GUDOLLE; ANTONELLO; FLACH, 2012).

Essa abordagem pode ser considerada como parte do paradigma de análise interpretacionista ou simbólicointerpretacionista nas ciências sociais, em particular na teoria organizacional (YANOW, 2000), em que uma visão voluntarista do ser humano, em uma relação dialética com as realidades estruturais, constrói a realidade social, subjetivamente dotada de sentido (BERGER; LUCKMANN, 2002). Como implicações, tem-se a ênfase no coletivo, nas ações e interações das pessoas, na linguagem e nos significados intersubjetivos de símbolos, valores, mitos, crenças e artefatos construídos em contextos específicos de interação (WEICK; WESTLEY, 2004; YANOW, 2000).

Segundo Brown e Duguid (1991), as instruções formais nem sempre são adequadas, daí se realizarem trocas informais entre os mais experientes e os pouco experientes, ou seja, mestres e aprendizes. A aprendizagem acontece, e o conhecimento é gerado por meio de conversações e interações entre as pessoas, uma vez que a participação nas práticas sociais se constitui modo fundamental de aprender algo. Assim, muito do conhecimento crítico não existe no papel, nem na mente dos indivíduos, mas na comunidade como um conjunto. A aprendizagem consiste em construção social e processo político, entrelaçada com 
a cultura organizacional e resultante da interação entre pessoas, manifestando-se nos comportamentos cotidianos (EASTERBY-SMITH; ARAUJO，2001; ELKJAER, 2001).

A aprendizagem manifesta-se no modo como as pessoas se comportam quando estão trabalhando com as outras, e esses padrões de comportamento são normalmente aprendidos na comunidade pelo processo de socialização (LAVE; WENGER, 1991, 2013; WENGER, 2013; WENGER; $\quad$ WENGER, 2015; SCHNEIDER，2012). Lave e Wenger (1991) acreditam que há uma forte ligação entre aprendizagem e prática do trabalho e exploram as relações concretas entre as pessoas, pois acreditam que os aprendizes assimilam conhecimentos e adquirem habilidades à medida que participam de uma comunidade junto a outros profissionais.

Na perspectiva da ação situada, a noção de contexto não é mais considerada como recipiente da ação, mas como situação que propicia o encontro dos interesses de agentes com as oportunidades, mediadas pelas restrições do ambiente no qual se encontram, influenciando-se mutuamente

(ANTONELLO; AZEVEDO, 2011; WENGER, 2013; WENGER; WENGER, 2015; SCHNEIDER, 2012). Para Gherardi,
Nicolini e Odella (1998), a aprendizagem desenvolvida no local de trabalho deve ser entendida como uma atividade social e cognitiva. Desempenha uma função prática, na medida em que enfatiza a importância da aplicação do conhecimento num contexto social.

Para Wenger (2003), em um sistema de aprendizagem social, a competência é histórica e socialmente definida, estando sempre em interação com a experiência de cada indivíduo, e o aprendizado em constante movimento exibe competências definidas em comunidades sociais. Ao mesmo tempo, competência e experiência podem estar em relações variadas uma com a outra, desde muito congruentes até muito divergentes. Sempre que os dois componentes estão em tensão, o aprendizado ocorre. Assim, a aprendizagem é definida a partir da interação entre competência social e experiência pessoal (WENGER, 2003; WENGER, 2013; WENGER; WENGER, 2015; SCHNEIDER, 2012).

O quadro é complexo e dinâmico, pois as experiências de vida e os padrões sociais de competência das comunidades não são necessariamente congruentes, e cada pessoa vivencia o aprendizado de um modo próprio. Para os aprendizes, sejam principiantes ou veteranos, tal vivência sempre envolve dois componentes: a 
competência que as comunidades estabeleceram ao longo do tempo (como agir para ser reconhecido como um membro competente) e a experiência contínua do mundo tanto como membro no contexto de uma dada comunidade, quanto além dela (WENGER, 2003).

O pertencimento a sistemas sociais de aprendizagem pode assumir várias formas em diferentes níveis de interação local e participação global. De acordo com Wenger (2003), há três modos de pertencimento:

a. Engagement (envolvimento): as formas pelas quais as pessoas se envolvem umas com as outras e com o mundo social modelam profundamente a experiência de quem são. Aprendem o que podem fazer e como o mundo responde a suas ações (por exemplo, fazendo coisas juntos, conversando, produzindo artefatos);

b. Imaginação: construção da imagem que as pessoas têm de si, das comunidades a que pertencem e do mundo, destinada a orientá-las ao refletir sobre a sua situação e ao explorar possibilidades (por exemplo, desenhando mapas, contando histórias ou construindo um conjunto de possíveis cenários para entender as opções de alguém). Essas imagens são essenciais para os indivíduos desenvolver um autossenso e interpretar sua participação no mundo;

c. Alinhamento: a certeza de que as atividades locais são suficientemente alinhadas com outros processos que possam ser eficazes (por exemplo, seguir o método científico, agir conforme um código moral ou discutir decisões importantes com cônjuges). $\mathrm{O}$ conceito não implica um processo de mão única de submeter-se a uma autoridade externa, mas um processo mútuo de coordenar perspectivas, interpretações e ações para que eles percebam objetivos e mais elevados.

Cada um desses modos de pertencimento contribui de maneira particular para formar os sistemas de aprendizagem social e as identidades pessoais, ou seja. Os modos podem ser conflitantes e complementares. Daí a utilidade de desenvolvê-los em combinação, equilibrando as limitações de um com o trabalho do outro.

\section{APRENDIZAGEM COMUNIDADES DE PRÁTICA}

EM

Ao lado da participação nos sistemas de aprendizagem e da identidade ali construída, as ações situadas também fazem parte central da dinâmica. Elas ocorrem no âmbito de uma comunidade de 
prática (LAVE; WENGER, 1991；2013), isto é, um sujeito coletivo que implica envolvimento mútuo e compartilha um repertório de ações, estilos de artefatos, conceitos, discursos e histórias. É ali onde se define histórica e socialmente a competência. Embora desenvolvido por Brown e Duguid (1991; 1998), dentre outros, o conceito de comunidades de prática foi formulado originalmente por
Lave e Wenger (1991): "um sistema de relações entre pessoas, atividades e o mundo, desenvolvida com tempo, e em relação de sobreposição e de tangencilidade a outras comunidades de prática é uma condição intrínseca da existência de conhecimento".

No Quadro 1, encontram-se sintetizados os principais indicadores de uma comunidade de prática.

Quadro 1 - Indicadores de comunidades de prática

\begin{tabular}{|ll|}
\hline \multicolumn{1}{|c|}{ Indicadores } \\
\hline 1. & Relações mútuas sustentadas, sejam elas harmoniosas ou conflituosas \\
\hline 2. & Maneiras compartilhadas de engajamento para fazer as coisas juntos \\
\hline 3. & Rápido fluxo de informações e propagação de inovações \\
\hline $\begin{array}{l}\text { 4. } \\
\text { processo em curso }\end{array}$ & Ausência de comentários introdutórios, como se conversas e interações fossem continuação de um \\
\hline 5. & Rápida exposição de um problema a ser discutido \\
\hline 6. & Coincidência substancial nas descrições dos participantes \\
\hline 7. & Saber o que os outros sabem, o que podem fazer e como podem contribuir para o empreendimento \\
\hline 8. & Identidades definidas mutuamente \\
\hline 9. & Habilidade para acessar de maneira apropriada ações e produtos \\
\hline 10. & Ferramentas, representações e outros artefatos específicos \\
\hline 11. & Histórias locais compartilhadas, piadas internas, maneiras conhecidas de rir \\
\hline 12. Jargões e expressões (atalhos) na comunicação, assim como facilidade para produzir novos \\
\hline 13. Certos estilos reconhecidos como indicadores de que alguém é membro da comunidade \\
\hline 14. Discurso comum refletindo certa perspectiva de mundo \\
\hline
\end{tabular}

Fonte: Adaptado de Wenger (1998; 2003; 2013; 2015) e Cox (2005)

De acordo com Wenger (2003), os seres humanos, desde o início da história, formaram comunidades que partilham práticas culturais refletindo a sua aprendizagem coletiva. Participar dessas “comunidades de prática" é a própria essência daquilo que nos torna seres humanos capazes de um saber significativo (WENGER， 2003; $\quad$ FIORENTINI; CARVALHO, 2015).

Wenger (2003) argumenta que as comunidades de prática são os blocos básicos de construção de um sistema social de aprendizagem, porque são "containers" sociais das competências que compõem tal sistema. Ao participar dessas comunidades, os participantes se definem uns aos outros e aquilo que constitui a competência em determinado contexto. Comunidades de prática definem a competência ao combinar três elementos (ROBERTS, 2006; WENGER, 2003; WENGER, 2006): o senso de empreendimento conjunto, o engamento mútuo e o repertório 
compartilhado. No primeiro elemento, os membros desenvolvem coletivamente o senso de empreendimento conjunto (joint enterprise), sobre o que é a sua comunidade e suas responsabilidades. Ser competente é entender o empreendimento bem o suficiente para ser capaz de contribuir. No segundo, os membros constroem sua comunidade por meio do engajamento mútuo (engagement). Eles interagem uns com os outros, estabelecendo normas e relações de reciprocidade que refletem essas interações. Ser competente significa ser capaz de se envolver com a comunidade e ser confiável como parceiro nessas interações. E, por fim, no terceiro, as comunidades de prática têm produzido um repertório compartilhado (shared repertoire) de recursos comuns (línguas, rotinas, sensibilidades, artefatos, ferramentas, histórias, estilos e assim por diante). Ser competente compreende ter acesso a tal repertório e ser capaz de usá-lo adequadamente.

Entretanto, comunidades de prática não podem ser romantizadas; elas nascem da aprendizagem, mas também podem aprender a não aprender. Para cada um dos três elementos mencionados como definidores da competência, podem-se apontar restrições:
- Enterprise (nível de energia de aprendizagem): quanta iniciativa a comunidade toma para manter a aprendizagem no centro de seu empreendimento? A comunidade deve mostrar liderança para impulsionar o seu desenvolvimento e manter um espírito de investigação. É preciso reconhecer e lidar com as lacunas em seu conhecimento, bem como permanecer aberto às direções emergentes e de oportunidades.

- Mutualidade (profundidade do capital social): quão profundo é o senso de comunidade gerado pelo compromisso ao longo do tempo? As pessoas devem conhecer-se suficientemente bem para saber como interagir de forma produtiva e para quem pedir ajuda ou conselhos. Devem confiar uns nos outros, não apenas pessoalmente, mas também na sua capacidade de contribuir para o empreendimento da comunidade, de modo que se sintam confortáveis abordando problemas reais juntos e para falar a verdade.

- Repertório (grau de autoconsciência): quanto autoconsciente é a comunidade sobre o repertório que está desenvolvendo e seus efeitos sobre a sua prática? Os conceitos, linguagem e ferramentas de uma comunidade de prática encarnam sua história e sua 
perspectiva sobre o mundo. Ser reflexivo em seu repertório permite à comunidade entender seu próprio estado de desenvolvimento a partir de múltiplas perspectivas, reconsiderar hipóteses e padrões, descobrir as possibilidades ocultas e, ainda, usar esse autoconhecimento para avançar.

Para que seja possível compreender como essas dimensões se manifestam na prática, uma comunidade deve olhar para os seguintes elementos: eventos, liderança, conectividade, adesão, projetos e artefatos (WILSON, 2002; O'DELL; HUPERT, 2011; WENGER, 2006; LAVE; WENGER, 2013).

- Eventos: se bem ajustados ao propósito da comunidade, vão ajudar a desenvolver uma identidade. A comunidade terá de decidir sobre o tipo de atividades de que precisa - reuniões formais ou informais, sessões para resolução de problemas ou oradores convidados. Também terá de considerar o ritmo desses eventos, que pode mudar com o tempo ou passar por ciclos.

- Liderança: dependem de líderes internos, que ajudam a comunidade a se desenvolver. O papel de "coordenador da comunidade" é fundamental, mas são necessárias múltiplas formas de liderança. Estas tanto podem concentrar-se em um ou dois membros, quanto ser amplamente distribuídas. Também pode haver mudanças com o tempo.

- Conectividade: permitir uma rica trama de conectividade entre as pessoas, podendo envolver a intermediação.

- Adesão: uma comunidade deve ter tamanho significativo para despertar interesse, mas não ao ponto de o foco se tornar difuso e a participação não atingir a identidade das pessoas.

- Projetos de aprendizagem: aprofundam seu compromisso mútuo quando assumem a responsabilidade com base em uma agenda de aprendizagem. Atividades em direção a esse objetivo visam explorar o domínio do conhecimento, encontrar lacunas na prática da comunidade e definição de projetos para fechar essas lacunas.

- Artefatos: conjunto próprio de artefatos como documentos, ferramentas, histórias, símbolos, websites, e assim por diante. A comunidade tem de considerar os artefatos de que necessita e que tem a energia para produzir e manter, para que eles continuem a ser úteis com a evolução da comunidade.

Com base no exposto, é possível afirmar que, sem a energia de aprendizagem daqueles que tomam a iniciativa, a comunidade torna-se 
estagnada, sem um forte relacionamento de pertencimento, e dilacerada, sem a capacidade de refletir, tornando-se refém de sua própria história (WENGER, 2003; SIEDLOK; HIBBERT; SILLINCE, 2015; MELO, 2015). Portanto, é importante para cada comunidade de prática desenvolver mecanismos que permitam a reflexão sobre a sua atuação no sentido de identificar avanços e estagnações na trajetória.

\section{PROCEDIMENTOS METODOLÓGICOS}

A escolha da revisão teórica e do método constituem as lentes que o pesquisador irá utilizar para observar a realidade e analisar os resultados. Este trabalho tem como pano de fundo as mudanças pelas quais a pesquisa está passando atualmente no Brasil e as exigências impostas aos docentes e discentes de pós-graduação.

Optou-se pela elaboração de um estudo qualitativo básico, que Merrian (1998) define como uma investigação que procura desvendar e compreender um fenômeno, um processo, as perspectivas e a visão do mundo das pessoas envolvidas ou uma combinação desses elementos. Acredita-se que esse método é adequado para a análise profunda de relações sociais, já que tem como objetivo interpretar as intenções e os significados que os atores revelam, com base na visão de que a realidade é construída pela interação dos indivíduos com o seu mundo social.

O que caracteriza este tipo de estudo são: a construção de significados a partir das experiências vividas pelos participantes da pesquisa; a compreensão da natureza do ambiente e do significado para os participantes estarem neste ambiente; o processo de condução da pesquisa essencialmente indutivo; e a evidenciação do resultado da pesquisa por meio do relato do fenômeno investigado. Neste tipo de estudo, o pesquisador é o instrumento de pesquisa e o resultado final é descritivo.

Esta pesquisa, de natureza qualitativa e exploratória, teve como objetivo compreender o processo de aprendizagem à luz da Teoria da Aprendizagem Situada, mais especificamente em comunidades de prática, em um grupo de pesquisa, tendo como base o modelo de análise desenvolvido em Wenger $(2003 ; 2013)$ e identificando possíveis categorias de análise para pesquisas comparativas em outros grupos de pesquisa.

Dessa forma, trata-se de um estudo de caso. Segundo Bonoma (1985, p. 206207) o estudo de caso é adequado "quando um fenômeno é amplo e complexo, onde o corpo de conhecimentos existente é 
insuficiente para permitir a proposição de questões causais e quando um fenômeno não pode ser estudado fora do contexto no qual ele naturalmente ocorre". Os objetivos deste método não são a quantificação ou a enumeração, "mas, ao invés disto: (1) descrição; (2) classificação (desenvolvimento de tipologia); desenvolvimento teórico; e (4) o teste limitado da teoria. Em uma palavra, o objetivo é compreensão".

Para a realização desta pesquisa, foi escolhido o grupo de pesquisa Ecologia Quantitativa do Programa de PósGraduação em Ecologia da UFRGS, pois ele, além de poder ser considerado como referência em sua área de conhecimento devido à qualidade de suas pesquisas e à quantidade de produção científica, pode ser considerado uma comunidade de prática, pois atende aos requisitos apresentados por Wenger (1998; 2003; 2013) e Cox (2005) e ilustrados no Quadro 1.

Os dados foram coletados a partir de observação não participante, por três meses, do laboratório onde fica localizado o grupo. Além disso, realizaram-se entrevistas, a partir de um roteiro semiestruturado, com 12 membros do grupo, dos 23 que frequentam assiduamente o local. Os entrevistados foram escolhidos aleatoriamente, por acessibilidade e disponibilidade. As entrevistas foram realizadas no próprio ambiente de trabalho dos pesquisadores, gravadas com a autorização dos entrevistados e, posteriormente, transcritas. O Quadro 2 apresenta o perfil dos entrevistados.

Quadro 2 - Frequentadores do laboratório entrevistados

\begin{tabular}{|l|l|}
\hline Frequentadores do laboratório & Tempo de participação no grupo \\
\hline Professor titular & 14 anos \\
\hline Professor adjunto & 1 ano \\
\hline Pós-doutorando & 1 ano \\
\hline Doutorando A & 10 anos \\
\hline Doutorando B & 3 anos \\
\hline Mestrando A & 2 anos \\
\hline Mestrando B & 1,5 anos \\
\hline Bolsista de extensão & 4 anos \\
\hline Bolsista de iniciação científica A & 1 ano \\
\hline Bolsista de iniciação científica B & 2 meses \\
\hline Bolsista de iniciação científica C & 2 meses \\
\hline Funcionário técnico & 10 anos \\
\hline
\end{tabular}

Fonte: base de dados.

Os dados foram tratados com a técnica da análise de conteúdo, mais especificamente análise categorial, que desmembra os discursos em categorias, pautando-se pelo referencial teórico. A interpretação baseou-se na comparação das 
informações coletadas com a fundamentação teórica utilizada nesta pesquisa e com as reflexões dos investigadores. Seguiram-se as diretrizes propostas pela análise temática de Bardin (2009), segundo a qual o tema é a unidade de acepção que se desprende espontaneamente de um escrito avaliado, conforme critérios coerentes com a teoria que serve de direção à leitura. Assim, foram emergindo as categorias: (a) ambiente/contexto; (b) liderança; (c) conectividade; (d) aprendizagem formal/informal; (e) artefatos/não humanos, que serão detalhadas na seção de análise e discussão de resultados.

\section{APRESENTAÇÃO DO CASO: GRUPO DE PESQUISA EM ECOLOGIA QUANTITATIVA}

O Programa de Pós-Graduação em Ecologia foi criado em 1978 e faz parte do Instituto de Biociências da Universidade Federal do Rio Grande do Sul. Na avaliação da CAPES, os cursos de Mestrado e Doutorado do Programa obtiveram o conceito 6 .

A missão do programa é a formação e qualificação avançada de docentes, pesquisadores, consultores e técnicos para atividades de ensino, pesquisa e extensão em ecologia, dando condições ao aluno de mestrado e doutorado de: a) avançar o conhecimento científico na área de ecologia; b) propor novas linhas de atuação em pesquisa; c) diagnosticar problemas ambientais e elaborar propostas inovadoras de pesquisa; d) elaborar trabalhos para publicações especializadas; e) interpretar, avaliar e sugerir temas de pesquisa; f) assessorar instituições públicas e privadas na emissão de pareceres e na solução de problemas ambientais.

Seguindo essas diretrizes, o grupo de pesquisa que atua no Laboratório de Ecologia Quantitativa tem desenvolvido teorias e métodos de análise em ecologia, envolvendo diferentes níveis de organização biológica, com ênfase nos campos do sul do Brasil, que se interpenetram com formações florestais, formando mosaicos. Os principais estudos estão voltados a: 1) análise da estrutura fenotípica e filogenética de metacomunidades; 2) análise de padrões em vegetação em diferentes escalas de tempo e espaço; 3) dinâmica de mosaicos campo-floresta, interações com clima, solo, dispersores de diásporos, herbivoria e fogo; 4) análise de séries paleoecológicas e de anéis de crescimento, incluindo mudanças globais no passado; 5) modelos de simulação de dinâmica de vegetação; 6) amostragem em comunidades e ecossistemas; 7) testes de hipóteses e 
inferência probabilística em ecologia via testes de permutação e autorreamostragem; 8) partição de diversidade; 9) desenvolvimento de algoritmos de análise e sua implementação em programas de computador. A produção científica do grupo pode ser acessada, na íntegra, na página

ecoqua.ecologia.ufrgs.br/publication.html.

O grupo de pesquisa, localizado no Campus do Vale da UFRGS, é composto por quarenta e quatro pessoas, sendo seis professores colaboradores externos e quinze alunos egressos. Entre os vinte e três frequentadores do laboratório estão: um professor titular, três professores adjuntos, três pós-doutorandos, sete doutorandos, três mestrandos, quatro bolsistas de iniciação científica, um bolsista de extensão e uma técnica. A descrição dos membros do grupo de pesquisa aponta para o atendimento do sexto indicador de uma comunidade de prática - a coincidência substancial nas descrições dos participantes.

\subsection{Análise e discussão dos resultados}

O primeiro contato com o grupo de pesquisa deu-se na forma de uma conversa com o professor titular do grupo, que fez questão de apresentar a filosofia de trabalho estabelecida para o grupo que, em sua análise, inclui autogestão, liberdade, interação, respeito e inexistência de hierarquia (mesmo havendo cargos e funções). $\mathrm{O}$ professor vê os estudantes/pesquisadores que trabalham no laboratório como filhos, sem haver um preferido nem motivo para competição, mas sim o estímulo à interação e à troca. Ele salienta a importância de respeitar a autoria dos trabalhos e ideias para que o compartilhamento continue, o que vem a representar o primeiro indicador de comunidades de prática - a evidenciação de relações mútuas sustentadas, sejam elas harmoniosas ou conflituosas. Conforme seu depoimento:

Não há espaços definidos: cada um que chega se ajeita de acordo com o espaço e interação com o grupo, e resolvem seus próprios conflitos. Para formar pesquisadores, é importante a criação de um ambiente que permita a autonomia e independência. Os alunos me consultam somente para burocracias relacionadas a verbas, mas, sobre questões técnicas e decisões, são bastante independentes e, muitas vezes, já apresentam a decisão tomada.

Todos os membros do grupo entrevistados parecem compartilhar a filosofia de trabalho e sentem-se motivados pela autogestão. Apesar das rotinas diárias incluírem as viagens de trabalho de campo para coleta de dados, análise estatística no laboratório, descrição dos resultados, 
contabilidade do projeto e reuniões em duplas ou de todo o grupo, cada um define seus dias e horários de trabalho, a partir de sua disponibilidade. Essa percepção evidencia o segundo indicador das comunidades de prática, que são as maneiras compartilhadas de engajamento para fazer as coisas juntos.

Também fazem parte da rotina do laboratório conversas informais, almoços conjuntos e intervalos frequentes para o cafezinho. Durante todo o dia de trabalho, o chimarrão, hábito comum entre os gaúchos, circula livremente, passando de mão em mão, o que pode ser interpretado como décimo indicador das comunidades de prática, representado por ferramentas, representações e outros artefatos específicos. Essa é uma forma de os membros do grupo se comunicarem, assimilando não só os procedimentos técnicos, mas os valores, normas e procedimentos informais do grupo. Nos almoços, as conversas são mais longas, e o grupo discute o ambiente de trabalho e a participação dos demais membros, avaliando se está de acordo com o grupo. Assim, à medida que interagem com o ambiente e com os colegas, aprendem/constroem as práticas (BROW; DUGUID, 1991; COSTA, 2011). A descrição dos referidos hábitos contribui para consolidar o terceiro e o quarto indicador das comunidades de prática, a saber: o rápido fluxo de informações e propagação de inovações; e a ausência de comentários introdutórios, como se conversas e interações fossem continuação de um processo em curso.

Apesar de cada um trabalhar na sua pesquisa em particular, seja trabalho de iniciação científica, artigo, dissertação ou tese, todos se reúnem praticamente todos os dias para trabalhar no laboratório, ao invés de trabalhar de modo isolado. Afinal, as pesquisas individuais fazem parte de um projeto maior, que recebe financiamento. Seja como for, quando os trabalhos de pesquisa como teses e dissertações estão entrando na fase final, as pessoas preferem trabalhar um pouco mais em casa para ter concentração e silêncio.

De acordo com os participantes, o objetivo do grupo é desenvolver pesquisa em ecologia e publicar. Além disso, todos os participantes fazem questão de ressaltar que se reúnem para compartilhar conhecimento e ajudar-se e que se sentem motivados em fazer parte do grupo, confirmando, assim, o segundo indicador das comunidades de prática - a preferência dos membros em realizar as atividades coletivamente - e o sétimo indicador, segundo o qual as pessoas do grupo social se conhecem mutuamente e sabem quem pode contribuir de determinada forma. 
Essa ênfase no coletivo, nas ações e interações das pessoas vem ao encontro das características da aprendizagem situada mencionadas por Weick e Westley (2004) e Yanow (2000).

Os temas para pesquisa, que devem estar sempre aderentes à linha de estudos do grupo e do pesquisador-chefe ou orientador e atualizados com as tendências da área, são definidos de acordo com as possibilidades de recursos e oportunidades para editais. Fica muito claro que as definições de projetos são participativas em reuniões formais e informais, onde todos participam e têm voz ativa, facultando a identificação do nono indicador das comunidades de prática, referente à habilidade de acessar de forma apropriada os artefatos e produtos. Contudo, o vetor determinante para orientar o foco para os projetos de pesquisa é a viabilidade financeira, pois os artefatos utilizados para coleta e análise dos dados são bastante dispendiosos. Todos demonstram estar cientes disso.

De acordo com Wenger (2003; 2013), os projetos de aprendizagem aprofundam o compromisso mútuo quando assumem a responsabilidade por uma agenda de aprendizagem. $\mathrm{O}$ engajamento de todos os membros na definição, pelo menos em parte, dos projetos, parece estar voltado a explorar o domínio do conhecimento, encontrar lacunas na prática da comunidade e definir projetos para preenchê-las.

Apesar de não haver progressão hierárquica, é possível perceber uma progressão natural de bolsista de iniciação científica a doutorando. Todos os participantes afirmam que aprenderam e continuam aprendendo muito por participar do grupo, mais do que a partir de atividades formais do programa. Essa comunidade de prática tem produzido um repertório compartilhado (shared repertoire) de recursos comuns, propiciando condições favoráveis para desenvolver competências, a partir da participação e da evolução no grupo (WENGER, 2003; 2013). A constatação faculta a identificação do décimo quarto indicador de uma comunidade de prática: o compartilhamento da visão do mundo pelos membros do referido grupo social.

Por ser um programa de pósgraduação, o aprendizado formal é realizado em salas de aula, seminários e leituras de artigos científicos, além da participação em eventos da área. As reuniões com o grupo e com o orientador também são apontadas como momentos de aprendizado, reforçando a forte presença do elemento "evento" (WILSON, 2002; O'DELL; HUPERT, 2011; WENGER, 2006; LAVE; WENGER, 2013). O 
aprendizado informal em conversas individuais com os colegas no momento do cafezinho, compartilhando experiências nas pesquisas em campo e no laboratório foi apontada por todos como o grande diferencial e que contribui sobremaneira para o aprendizado. Alguns depoimentos ilustram:

Diversas atividades (viagens, trabalhos em conjunto, e discussões) me fizeram crescer profissional e pessoalmente. Acredito que as relações pessoais estimulam e contribuem diretamente para o meu processo de aprendizado; [...] não existe aprendizado sem interação, e a interação é melhor com intimidade, ou seja, entre amigos; a gente está sempre discutindo temas científicos que fazem parte do trabalho de cada um, no café, no almoço, em reuniões que a gente costuma marcar um com o outro, não as do grupo todo. Acho que a interação é um "tchã".

Todos os integrantes do grupo entrevistados afirmam que os relacionamentos influenciam muito a aprendizagem, dando mais vontade e interesse de a pessoa crescer naquele grupo, o que aumenta a produtividade, tanto individual como coletiva, e leva à discussão qualificada dos temas, mesmo de maneira informal. Um depoimento ilustra: "eu gosto bastante de fazer parte deste grupo de pesquisadores muito bons e grandes amigos [...] acho que todo mundo meio que 'pega' junto, as pessoas participam, se envolvem com um grupo com diferentes intensidades, é que estamos ligados por redes de projetos, entende?”.

Para Lave e Wenger (1991) a aprendizagem se manifesta no modo como as pessoas se comportam quando estão trabalhando com as outras, e esses padrões de comportamento são normalmente aprendidos na comunidade pelo processo de socialização. $\mathrm{O}$ aprendizado informal a partir das interações sociais é bastante valorizado pelos membros do grupo, mais que o aprendizado formal, confirmando as noções de Brown e Duguid (1991).

É possível perceber orgulho nos participantes por fazerem parte do grupo. São destacados valores como ser competente e de fazer sua formação com pesquisadores de alto nível, pois isso assegura a verba para a pesquisa, confirmando a existência do oitavo indicador da comunidade de prática que se refere a identidades definidas mutuamente. Também são destacadas: (i) a relação de união entre os participantes do grupo, (ii) a descontração e (iii) o ambiente de apoio dos colegas. Alguns salientam que há encontros fora do ambiente de trabalho. Mesmo após a saída do grupo de pesquisa, os participantes fazem questão de manter o contato social. Nas palavras de um dos doutorandos: 
Somos o melhor grupo da ecologia da UFRGS! mais organizados, ricos, competentes... como grupo, pois chefe bom = grupo bom. Ele é muito competente, dedicado, estimula muito o contato com outros grupos de pesquisa, aqui ou no exterior, tem muitas parcerias, publica um monte, logo tem bala na agulha p'ra escrever um projeto caro e receber recurso, e seleciona bem os orientados. Acho que descontração é um diferencial, mas ao mesmo tempo com responsabilidade.

Essas descrições e depoimentos salientam o senso de empreendimento conjunto (joint enterprise) da referida comunidade de pesquisa, que contribui para o compartilhamento da visão da realidade (décimo quarto indicador da comunidade de prática), bem como de suas responsabilidades (LAVE; WENGER, 1991; WENGER 2003).

Em relação às competências valorizadas pelo grupo, foram pouco apontados os conhecimentos em biologia e ecologia, e um pouco de estatística, que podem ser consideradas competências técnicas. As competências valorizadas referem-se mais a competências comportamentais como dedicação, responsabilidade e motivação para aprender e desenvolver as pesquisas. Características voltadas ao relacionamento com os colegas também foram destacadas. Quem apresenta essas características recebe mais apoio dos colegas antigos para desenvolver suas pesquisas. Essas observações demonstram que, mais do que conhecimentos, as competências relacionadas ao sistema social de aprendizagem e compartilhamento com o grupo são valorizadas. Assim, o knowing (WENGER, 2003; 2013) vai se desenvolvendo a partir do que a comunidade estabelece como competência e a experiência contínua dos membros na comunidade.

O papel da liderança foi muito salientado. É possível perceber que o perfil dos líderes formais e informais direciona as práticas diárias e proporciona um ambiente propício à aprendizagem social (WILSON, 2002; O’DELL; HUPERT, 2011; WENGER, 2006; LAVE; WENGER, 2013). A liderança formal está pautada nos professores que orientam as atividades, contribuem com idéias e são acessíveis. Em relação a um dos professores, um discente comenta: "o principal, sabe o que é, as pessoas o admiram e fazem a sua parte para poder retribuir e se manterem próximas. Ele é um excelente profissional".

Apesar de não estar estabelecida uma hierarquia formal, além de professor e aluno, é possível perceber que o nível acadêmico e de tempo de participação no grupo é relevante. Normalmente os 
doutorandos orientam a iniciação científica, respaldados pelos professores. Contudo, essa liderança não é imposta; quem tem mais conhecimento e experiência orienta os mais novos. Também são apontados líderes informais com capacidade de comunicação, normalmente mais experientes, que estimulam a integração do grupo e auxiliam em dúvidas e dificuldades. Um bolsista de iniciação científica valoriza: "são colegas muito legais, que contribuem a todo o momento com o nosso aprendizado".

Em relação aos diferentes níveis de participação/engajamento dos membros do grupo, alguns destacaram que todos estão engajados e que as pessoas podem ter um papel maior ou menor em um projeto específico, pois podem participar de vários, o que vem a representar o segundo indicador da classificação de um grupo social como comunidade de prática. A maior parte do grupo percebe que aqueles com maior nível de participação no grupo acabam tendo um maior aprendizado e que as pessoas há mais tempo no grupo são mais engajadas, enquanto as novas demoram um pouco para se sentirem pertencentes e ter maior participação. É salientado que estudo individual também é fundamental para o desenvolvimento do conhecimento teórico.
Uma das características que mais se destacam na pesquisa é o engajamento mútuo (engagement) dos membros, que estabelecem normas e relações de reciprocidade. As evidências decorrentes da observação não participante dos pesquisadores, bem como os trechos das entrevistas confirmam o teor da literatura revisada, segundo a qual ser competente é ser capaz de envolver-se com a comunidade e ser confiável como parceiro nas interações (WENGER, 2003; 2013).

Todos os participantes afirmaram que contribuem para o aprendizado do grupo, realizando suas atividades mais técnicas, possibilitando condições para o grupo se desenvolver, incentivando discussões sobre os temas de pesquisa, auxiliando os menos experientes e reconhecendo a contribuição dos demais membros.

Sobre o relacionamento com pessoas externas ao grupo, com outros laboratórios ou projetos, o laboratório é frequentado por muitos alunos de outros grupos de pesquisa, especialmente os mais próximos e com temas semelhantes. Diariamente há algum aluno ou professor que vem ao laboratório utilizar os computadores, pedir auxílio para utilizar os softwares estatísticos ou para tomar um cafezinho. Além disso, há projetos em conjunto com outros grupos e prestação de 
serviços em conjunto com outros grupos. Os membros argumentam que o bom relacionamento com outros grupos contribui para o aprendizado, outras experiências e novas idéias. Alguns acham que a interação é adequada, outros acham que poderia ser melhor.

Em relação à reflexão individual e ao aprendizado a partir desse distanciamento, a maioria dos membros disse questionar-se sobre a postura no grupo, buscando interagir melhor com os colegas, participar mais e corrigir erros. $\mathrm{O}$ grau reflexivo de autoconsciência do grupo, que permite à comunidade entender seu próprio estado de desenvolvimento por múltiplas perspectivas, reconsiderar hipóteses e padrões, descobrir as possibilidades ocultas e usar esse autoconhecimento para avançar (WENGER, 2003; 2015) foi muito difícil de identificar. Conseguiu-se verificar algumas reflexões sobre a conduta individual e do grupo, mas é uma dimensão de difícil análise.

Ficou evidente a importância dos artefatos não humanos nas práticas diárias e aprendizado do grupo (WILSON, 2002; O'DELL; HUPERT, 2011; WENGER, 2006; LAVE; WENGER, 2013). Todas as atividades diárias de pesquisa em campo ou de análise dependem de uma série de equipamentos, softwares e um planejamento muito grande de cronograma e transporte. São diversas as reuniões para planejar a combinação de recursos para as atividades de coleta de dados. A pessoa que presta suporte técnico e os bolsistas diariamente organizam tais rotinas e fazem a contabilidade.

A relação com os computadores é muito pessoal, pois, apesar de não haver um local definido, todos os dias as pessoas sentam-se nos mesmos lugares e utilizam o mesmo computador. $\mathrm{O}$ layout do laboratório reflete a filosofia de trabalho: o laboratório é dividido por divisórias em quatro espaços, sem porta e os vidros foram retirados para permitir maior contato entre as pessoas. A sala por onde as pessoas entram é a de reuniões, e as demais têm mesas e computadores. As pessoas sentam próximas por afinidades pessoais. A sala do fundo, perto da janela, é a mais frequentada. É onde se localizam a pia, a cafeteira e os equipamentos para o chimarrão.

Conforme Wenger (2003), a comunidade tem de considerar os artefatos de que necessita e que tem a energia para produzir e manter, para que eles continuem a ser úteis com a evolução da comunidade. Os participantes não humanos dessa comunidade têm um papel ativo e muito importante, sem os quais as relações e aprendizado da comunidade, com certeza, 
seriam diferentes e, provavelmente, menos profundas.

\section{CONSIDERAÇÕES FINAIS}

Visando contribuir para o avanço de conhecimentos científicos, esta pesquisa teve como objetivo compreender como ocorre a aprendizagem, à luz da abordagem da aprendizagem situada, em uma comunidade de prática. Visando proporcionar um maior conhecimento sobre o tema, ainda pouco explorado, pretendeu-se identificar possíveis categorias de análise para futuras pesquisas comparativas com outros grupos de pesquisa.

Fazem parte da rotina do laboratório as conversas informais, almoços conjuntos e intervalos para o cafezinho, além da presença frequente do chimarrão. Essas são formas de os membros do grupo se comunicarem, de assimilarem não só os procedimentos técnicos, mas os valores, normas e procedimentos informais do grupo. Os participantes, que mencionam como prática comum se reunirem para compartilhar conhecimento e ajudar-se, sentem-se motivados para continuar a fazer parte do grupo.

Todos os entrevistados afirmam que aprenderam e continuam aprendendo muito por participar do grupo, mais do que a partir de atividades formais do programa. Essa comunidade de prática tem produzido um repertório compartilhado (shared repertoire) de recursos comuns o qual vai se tornando mais competente a partir da participação e da evolução no grupo.

Foi possível perceber orgulho dos participantes em fazer parte do grupo. São destacados valores como serem competentes e produtivos e, em função disso, terem acesso a uma relevante verba para a pesquisa. Os alunos do programa salientam, ainda, o fato de estarem fazendo sua formação com pesquisadores de alto nível.

Competências comportamentais e relacionais são muito valorizadas pelos membros do grupo, mais do que as competências técnicas. Essas observações demonstram, que mais que conhecimentos, as competências relacionadas ao sistema social de aprendizagem e compartilhamento com o grupo são valorizadas.

O papel da liderança também foi muito salientado, e foi possível perceber que o perfil dos líderes formais e informais direciona as práticas diárias, além de proporcionar um ambiente propício à aprendizagem social. A liderança formal está pautada nos professores que orientam 
as atividades, contribuem com ideias e são acessíveis.

Em relação aos diferentes níveis de participação/engajamento dos membros do grupo, alguns destacaram que todos são engajados, podendo ter um papel maior ou menor em um projeto específico, pois podem participar de vários. Com isso, há uma constante interação entre todos os membros.

Ficou clara a importância dos artefatos nas práticas diárias e aprendizado do grupo. Todas as atividades diárias de pesquisa em campo ou de análise dependem de uma série de equipamentos, softwares e um planejamento muito grande de cronograma e transporte. Além disso, há a relação pessoal muito forte entre os membros do grupo e os seus respectivos computadores já que, por serem frequentadores assíduos, cada um costuma utilizar sempre o mesmo equipamento.
Este trabalho, pelo seu caráter exploratório, é o ponto de partida para a análise de grupos de pesquisa, a partir da aprendizagem contextualizada no ambiente social onde esta ocorre. Sugere-se que novos estudos, inclusive comparativos, sejam realizados com outros grupos de pesquisa, identificando as semelhanças e particularidades nas práticas de trabalho e relações, bem como suas relações com os resultados.

Por fim, a Teoria da Aprendizagem Situada e o conceito de comunidades de prática mostraram-se adequados para a análise de grupos de pesquisa científica. Contudo, identificar e analisar as reflexões da comunidade foi uma tarefa desafiadora, que não foi atingida na íntegra. O modelo e os dados coletados não possibilitaram a análise de: a) negociações; b) relações de poder; e c) conflitos na comunidade. 


\section{REFERÊNCIAS}

ANTONELlO, C. S. Contextos do Saber e Aprendizagem Informal. In: ANTONELLO, C. S.; GODOY, A. S. (Eds.) Handbook de Aprendizagem Organizacional. Porto Alegre: Bookman, 2011.

ANTONELLO, C. S.; AZEVEDO, D. Aprendizagem Organizacional: explorando o terreno das teorias culturais e das teorias baseadas em práticas. In: ANTONELLO, C. S.; GODOY, A. S. (Eds.) Handbook de Aprendizagem Organizacional. Porto Alegre: Bookman, 2011.

ANTONELlO, C. S.; GODOY, A. S. Aprendizagem Organizacional e as Raízes da Polissemia. In: ANTONELlO, C. S.; GODOY, A. S. (Eds.) Handbook de Aprendizagem Organizacional. Porto Alegre: Bookman, 2011.

BARDIN, L. Análise de conteúdo. Edição revista e actualizada. Lisboa: Edições 70, 2009.

BASTOS, A.V.B.; GONDIM, S.M.G.; LOIOLA, E. Aprendizagem organizacional versus organizações que aprendem: características e desafios que cercam essas duas abordagens de pesquisa. R. Adm - Revista de Administração, v. 39, n. 3, 2004, São Paulo, p. 220-30.

BERGER, P.L.; LUCKMANN, T. A construção social da realidade: tratado de sociologia do conhecimento. 22. ed. Petrópolis: Vozes, 2002.

BONOMA, T. V. Case research in marketing: opportunities, problems, and a process. Journal of marketing research, v. 30, n. 4, 1985, p. 99-208.

BRITO, M. C. P. S. Impacto da Introdução das TICs na Partilha do Conhecimento em CoP na Organização: Um estudo de caso numa organização cooperativa de crédito. Dissertação (Mestrado em Estatística e Gestão de Informação), Lisboa: Universidade Nova de Lisboa, 2012.

BROWN, J.S.; DUGUID, P. Organizational learning and Communities-of-Practice: Toward a unified view of working, learning, and innovation. Organizational Science, v. 2, n. 1, 1991, p. $58-82$.

COX, A. What are communities of practice? A comparative review of four seminal works. Journal of Information Science, v. 31, n. 6, 2005, p. 527-540. 
EASTERBY-SMITH, M.; ARAUJO, L. Aprendizagem organizacional: oportunidades e debates atuais. In: EASTERBY-SMITH, M.; BURGOYNE, J.; ARAUJO, L. (orgs.) Aprendizagem organizacional e organizações de aprendizagem: desenvolvimento na teoria e na prática. São Paulo: Atlas, 2001.

EASTERBY-SMITH, M.; SNELL, R.; GHERARDI, S. Organizational learning: diverging communities of practice? Management learning, v. 29, n. 3, 1998, p. 259-272.

ELKJAER, B. Em busca de uma teoria de aprendizagem social. In: EASTERBY-SMITH, M.; BURGOYNE, J.; ARAUJO, L. (orgs.) Aprendizagem organizacional e organizações de aprendizagem: desenvolvimento na teoria e na prática. São Paulo: Atlas, 2001.

FIORENTINI, D.; CARVALHO, D. L. O GdS como lócus de experiências de formação e aprendizagem docente. In: FIORENTINI, D.; FERNANDES, F. L. P.; CARVALHO, D. L. (Org.). Narrativas de Práticas de Aprendizagem Docente em Matemática. São Carlos: Pedro \& João Editores, 2015, p. 15-37.

GHERARDI, S.; NICOLINI, D.; O.F. What Do You Mean By Safety? Conflicting Perspectives on Accident Causation and Safety Management in a Construction Firm. Journal of Contingencies and Crisis Management, v. 6, n. 4, 1998.

GUDOLLE, L.S.; ANTONELLO, C.; FLACH, L. Aprendizagem situada, participação e legitimidade nas práticas de trabalho. RAM, REV. ADM. MACKENZIE, v. 13, n. 1, São Paulo, jan./fev. 2012.

HANDLEY, K. et al. Within and Beyond Communities of Practice: Making Sense of Learning Through Participation, Identity and Practice. Journal of Management Studies, May 2006.

LAVE, E; WENGER, J. Situated Learning and Legitimate Peripheral Participation Cambridge: Cambridge University Press, 1991.

LAVE, J.; WENGER, E. Situated Learning (Learning in Doing: Social, Cognitive and Computational Perspectives). Cambridge: Cambridge University Press, 2013.

MATOS, J. F. Aprendizagem como participação em CoP mediadas pelas TIC, Challengers, 2005 - IV Conferência Internacional sobre Tecnologias da Informação e Comunicação, 11-13 maio, Braga. Disponível em: <www.edu.fc.ul.pt/docentes/;fmatos/comunicacoes.html>. Acesso em: 10 nov. 2016. 
MELO, E. S. Comunidades de prática: um estudo de caso na Rede de Bibliotecas e Centros de Informação em Arte no Estrado do Rio de Janeiro - REDARTE/RJ. 2015. Dissertação (Mestrado em Biblioteconomia), Rio de Janeiro: Universidade Federal do Estado do Rio de Janeiro, 2015.

MERRIAM, S. B. Qualitative research and case study applications in education: resived and expanded from case study research in education. San Francisco: Jossey-Bass, 1998.

O'DELL, C.; HUPERT, C. The New Edge in Knowledge: How Knowledge Management Is Changing the Way We Do Business. Wiley, 2011.

OLIVEIRA, R.; SANTOS, V. Inserção inicial do futuro professor na profissão docente: contribuições do Estágio curricular supervisionado na condição de contexto de aprendizagem situada. Revista Educação Matemática Pesquisa, v. 13, n. 1, 2011, p. 36-49.

ROBERTS, J. Limits to Communities of Practice. Journal of Management Studies, v. 43, n. 3, p. 623-639, 2006.

SCHNEIDER, E. I. Uma Contribuição aos Ambientes Virtuais de Aprendizagem (AVA) suportados pela Teoria da Cognição Situada (TCS) para pessoas com deficiência auditiva. Dissertação (Mestrado em Engenharia e Gestão do Conhecimento), Florianópolis: PPEGC/UFSC, 2012.

SIEDLOK, F.; HIBBERT, P.; SILLINCE, J. From practice to collaborative community in interdisciplinary research contexts. Research Policy, v. 44, n. 1, p. 96-107, February, 2015.

WEICK, K. E.; WESTLEY, F. Organizational learning: confirming an oxymoron. In: CLEGG, S. R.; HARDY, C.; NORD, W. R. Handbook of organization studies, v. 3. São Paulo: Atlas, 2004.

WENGER, E.; WENGER, B. Learning in landscapes of practice: A framework. In: WENGER, E. et al. Learning in landscapes of practice. New York: British Library, 2015, p. 13-31.

WENGER, E. Communities of practice a brief introduction. Junho, 2006. Disponível em: <http://www.ewenger.com/theory/> Acesso em: 10 nov. 2016.

WENGER, E. Communities of Practice and Social Learning Systems. In: NICOLINI, D.; GHERARDI, S.; YANOW, D. (eds.). Knowing in Organizations: A Practice-Based Approach. New York: M.E. Sharpe, 2003. 
WENGER, E. Communities of Practice: Learning, Meaning, and Identity. Cambridge: Cambridge University Press, 1998.

WENGER, E. Uma teoria social da aprendizagem. In: Illeris, K. (org). Teorias contemporâneas da aprendizagem. Trad Ronaldo Cataldo Costa. Porto Alegre: Penso, 2013, p.246-257.

WILSON, T. D. The nonsense of 'knowledge management'. Information Research, v.8, n.1, Oct. 2002. Disponível em: <http://www.informationr.net/ir/8-1/paper144.html>. Acesso em: 10 nov. 2016.

YANOW, D. Seeing organizational learning: a 'cultural' view. Organization, 2000, v. 7, n. 2, p. 247-268. 